\title{
DIE PORTUGESE BYDRAE TOT DIE AFRIKAANSE WOORDESKAT: ENKELE PROBLEME.
}

Die teenwoordigheid van Portugese woorde in Afrikaans is toe te skryf aan die verspreiding van die Portugese taal in die wêreld. Aangesien hierdie verspreiding maar net 'n aspek van die totale Portugese koloniale gebiedsuitbreiding is, sal dit nodig wees, ten einde bogenoemde taalfenomeen te verstaan, dat ons vir' $n$ oomblik na die politieke geskiedenis van Portugal in hierdie tydperk lyk.

Naciat die Portugese konings van die eerste dinastie die Portugese gebiede uitgebrei en verenig het, kan die uitbreiding van Portugal in Europa as afgehandel beskou word. Dit het nog die moontlikheid van uitbreiding na Spaanse gebied gelaat. So 'n uitbreiding was die begeerte van die Portugese konings en het ook gelei tot die avontuur van Koning Fernando, 'n onderneming wat 'n katastrofiese uiteinde gehad het. Dit het egter nog nie die Portugese ideaal van uitbreiding laat verflou nie.

Met die kroning van Don Joao I as koning van Portugal (1384) het die invloed van die bourgeoisie toegeneem, en dit het nuwe uitbreidingsmoontlikhede geskep. Joao Afonso da Azambuja se voorstel om Ceuta aan te val het vir Portugal die rigting aangedui na 'n rewolusionêre en glorieryke gebiedsuitbreiding.

In 1418 het Prins Hendrik sy beroemde seevaartskool te Sagres gestig en hierdie datum kan beskou word as die aanvang van die seevaartavonture van die Portugese volk.

Die Portugese koloniale Ryk is dieselfde jaar gebore met die ontdekking van die eiland Madeira. Teen die einde van die vyftiende eeu was die hele weskus van Afrika reeds Portugese besit. 1498 staan bekend as die stigtingsjaar van die portugese Oosterse Ryk en in 1500 word hierdie Koloniale Ryk na die Amerikas uitgebrei. ${ }^{1}$ )

Die koloniale uitbreiding is nou verbind aan die Portugese taalverspreiding in die wêreld. ${ }^{2}$ ) Waar die Portugese seevaaraers ook al aangedoen het, is hulle taal in 'n vereenvoudigde leksikale en grammatikale vorm onmiddellik aangeneem as handelstaal tussen die Europeërs en die inboorlinge ("pidgin") (Kreools). " Op hierdie wyse het Kreools as taal in Afrika 
ontstaan in St Tomé, Ano Bom, Principe, Guineê en die Kaap Verdiese Eilande en ook in Asië in Macau, Java, Malaca, Ceylon, Goa, Damao, Diu, die kus van Malabar en die kus van Coromandel. ${ }^{5}$ )

Tydens die regering van Koning Joa III het die Portugese koloniale uitbreiding sy hoogtepunt bereik, maar onder dieselfde monarg begin die verbrokkeling van die Portugese Ryk. Die Spaanse oorheering van Portugal $(1590-1640)$ het hierdie proses van verbrokkeling versnel en die Portugese kolonies het Spanje se teenstanders, Nederland en Engeland, ten prooi geval.

Nedierland se hardnekkige pogings om die Portugese kolonies in te palm was in 'n groot mate suksesvol. Die volgende gebiede is deur die Nederlanders verower en ingeneem: die eilande van Molucas (1605), Pernambuco (1630 - 37), Ceylon (1638), Malaca, Maranhao en Luanda (almal in 1614) en die kus van Malabar $(1661-63){ }^{6}$ ) Sommige van hierdie kolonies is weer deur die Portugese herower (Brasilië en Angola), maar Nederland het die eilande van Molucas, Ceylon, Malaca en die kus van Malabar behou. Hiervan het verskeie later Engelse besittings geword.

Die stryd om koloniale heerskappy vind ook sy weerkaatsing in die taalsituasie. In die kolonies wat deur Nederland verower is, is daar gepoog om die Portugese taal en sy Kreoolse vorm te onderdruk ten gunste van Nederlands. Selfs die strengste maatreëls is met min sukses aangewend en Portugees het sy status in die kolonies behou. ${ }^{7}$ Die taalkundige stryd tussen Nederlands en Portugees het egter die voordeel gehad dat dit die twee tale in 'n kontaksituasie geplaas het. Hierdie wedersydse taalbeinvloeding het tot gevolg gehad dat Nederlands 'n sekere aantal woorde aan Portugees ontleen het, en omgekeerd. ${ }^{8}$ )

Die besluit van die Nederlands Oos-Indiese Kompanjie om 'n halfwegstasie aan die Kaap die Goede Hoop te stig het veroorsaak dat baie van hierdie Portugese woorde deur die Nederlandse koloniste na die suidpunt van Afrika gebring is. Sommige word vandag nog in Afrikaans gebruik; ander was twee of drie eeue gelede bekend, maar word vandag nie meer aangetref nie.

Die Lesluit van die Nederlancis Oos-Indiese Kompanjie om die 
Kaap in 'n permanente nedersetting te omskep het onmiddellik tot 'n aanvraag na arbeiders gelei. Aangesien die Hottentotte nie geskik was as werkers nie, het die Nederlanders op die invoer van slawe besluit. Aanvanklik is slawe van Madagaskar en van sekere Portugese gebiede in Afrika na die Kaap gebring, maar later het Asiatiese slawe voorkeur ge-kry. Baie was afkomstig van gebiede waar die Kreoolse vorm van Portugees die voertaal was: die kus van Malabar, die kus van Coromandel, Ceylon, die Golf van Bengale en Incionisië. ${ }^{9)}$

Die ontstaan van 'n Portugees-sprekende slawegemeenskap aan die Kaap het twee taalkundige invloede gehad wat vir ons op die oomblik van belang is: die bevestiging van Portugese leksikale elemente wat reeds in koloniale Nederlands aanwesig was, asook nuwe bydraes tot die woordeskat van Kaapse Nederlands, wat later Afrikaans sou word.

Die ondersoek na Portugese leksikale elemente in Afrikaans skep heelwat probleme: Hier volg 'n kort opsomming van die belangrikstes:

1. Die skaarste aan taalkundige dokumente veroorsaak dat dit nie altyd moontlik is om te bepaal of die leksikale element afkomstig is van die Portugese Kreools wat aan die Kaap gepraat en of dit reeds in Nederlands aanwesig was nie.

'n Voorbeeld van so 'n geval is die Afrikaanse woord daeraad (vissoort van familie van die Sparidae). Boshoff en Nienaber, ${ }^{10}$ ) in navolging van Franken, sien die oorsprong van die woord in die Portugees dorado, ${ }^{11}$ ) na hulle mening oorgedra deur die Nederlandse dorade. Die Woordeboek der Nederlandsche Taal, ${ }^{12}$ ) Van Wijk ${ }^{13}$ ) en De Vries ${ }^{14}$ ) maak egter geen melding van so 'n woord in Nederlands nie.

2. Die oënskynlike ooreenkoms tussen sekere vorms van Portugees, Spaans en Italiaans maak dit moeilik om vas te stel aan watter taal Afrikaans die woord ontleen het.

a) asgaai (Afrikaans spies)

Hierdie woord kan net sowel 'n ontlening aan die Spaans azagaya (= spies) as aan die Portugees azagaia (= spies) wees. Die feit dat die woord en die Nederlands van die sewentiende eeu gedokumenteer is (assa-/hassegay) ${ }^{15}$ ) 
en dat dit in die Kreools van Batavia bestaan het (assegaay $=$ Afrikaans spies) $)^{16}$ ) laat 'n mens tog wonder of dit nie aan Portugees ontleen is en so deel van Nederlands en later Afrikaans geword het nie. Dit moet ook nie vergeet word dat hierdie woord deur Portugees na nader Europese tale versprei is nie: ${ }^{17)}$ Afrikaans asgaai < Nederlands assegaai wsk < Kreools assegaaya < Portugees azagaia (sedert 15e eeu) < Arabies az-zagaia.

b) banana (= Afrikaans piesang)

Die vraag ontstaan of hierdie woord aan die Portugese banana (= piesang) of die Spaans banana (= piesang) ontleen is. Aangesien banana vir die eerste keer aangetref word in die werke van die Portugese skrywer Garcia da Orta $(1563)^{19}$ ) en die Portugese die woord aan Europa bekend gestel het, ${ }^{20}$ ) is dit nie onmoontlik dat Afrikaans dit aan Portugees ontleen het nie: Afrikaans banana Nederlands banana (sedert $16 \mathrm{e} \mathrm{eeu})^{21}$ ) $<$ Portugees banana (sedert 16e eeu) < Arabies banana ${ }^{22}$ ) $<$ Angolees banam. ${ }^{23}$ )

c) basta (Afrikaans genoeg)

Hierdie woord skep heelwat meer probleme as die voorafgaande voorbeelde. Is sy oorsprong die Spaanse basta (- genoeg), die Portugese basta (- genoeg) of die Italiaanse basta (- genoeg)? Sommige filoloë beskou dit as 'n lusitanisme in koloniale Nederlands, ${ }^{24}$ ) waarskynlik omdat dit ook bestaan het in die Portugese Kreools van Ceylon (basta): ${ }^{25)}$ Afrikaans basta $<$ Nederlands basta $^{\mathbf{2 6})}$ wsk < Kreools van Ceylon basta < Portugees basta (sedert 15e eeu) ${ }^{2} 7$ ).

d) Karet ( = Afrikaans bagasierak agteraan kar)

Die woord carreta ${ }^{28}$ ) kan ook Portugees, Spaans of Italiaans van oorsprong wees. Die Portugese afkoms blyk meer waarskynlik te wees as die ander twee, omdat die woord gedokumenteer is in die Kreools van Ceylon $(\text { careta })^{29)}$ sowel as in die Kreools van Batavia (caretta). ${ }^{30}$ ) Die Nederlanders kon hierdie woord aan enige van die twee Kreoolse dialekte ontleen het: Afrikaans karet Nederlands karet/karette wsk. < Kreools careta/caretta Portugees carreta < Provensaals-Katalaans - < carreta < Latyn carru ${ }^{31)}$ 
3. Die gebrek aan grondige kennis van die Portugese taal en sy dialekte, Kreools ingesluit, by Suid-Afrikaanse taalkundiges lei tot onvolledige verduidelikings en selfs verkeerde etimologieë.

\section{a) almaskie of maskie (= Afrikaans altemit, nietemin)}

Boshoff en Nienaber ${ }^{32}$ ) beskou dit as ' $n$ Portugese etimologie waarvan die oorspronklike vorm masque was, maar hierdie teorie lewer semantiese probleme op. Die bestaan van die woord maisque of masque in die Kreools van Ceylon ${ }^{33)}$ bevestig ons opinie dat die oorspronklike vorm van die leenwoord por mais que (-Afrikaans hoe meer, alhoewel) was: Afrikaans almaskie/maskie < Kreools maisque/masque < Portugees por mais que.

(b) daeraad (vissoort van die familie van die Sparidae)

Indien die woord sy oorsprong in die Nederlands dorade het, is die stamwoord nie dorado soos Boshoff en Nienaber $^{34}$ ) dit aangee nie, maar dourada. Die finale $e$ moet Nederlands vir die Portugese klank ( $e$ ) wees.

c) faikonta (- Afrikaans kamma, kwansuis).

Die stamwoord volgens Boshoff en Nienaber, ${ }^{36}$ ) fazia de conta, is nie korrek nie, want die vorm fai is 'n verbastering van faz en nie fazia nie. Dieselfde vorm het in die Kreools van Ceylon voorgekom, naamlik fai conta: ${ }^{36)}$ Afrikaans faikonta $<$ Kreools fai conta $<$ Portugees faz de conta.

d) fayson (= Afrikaans fisant) $\left.{ }^{3} 7\right)$

Die stamwoord wat deur Franken ${ }^{38}$ ) angegee word (faijao = boon) is foneties en semanties gesproke onmoontlik. Die Portugese stamwoord is faisao (-Afrikaans fisant); Afrikaans fayson < Portugees van die $16 \mathrm{e}$ eeu faison < Latyn phasianu-39)

e) jentoe (- Afrikaans los meisie, hoer).

Boshoff en Nienaber se mening is dat die oorsprong van die woord die Portugees gentio (= Afrikaans heiden) ${ }^{40}$ ) is. Die woord moes egter ook invloed ondergaan het van die Portugees gentio wat gedurende die sestiende eeu die betekenis van "vroue" 11 ) gehad het: Afrikaans jentoe < Portugees gentio + Portugees van die $16 \mathrm{e}$ eeu gentio. 


\section{f) nonna/nonje of nunje (= Afrikaans vrou, meisie)}

Die leenwoord nonna se oorspronklike vorm word normaalweg aanvaar as dona, ${ }^{4}$ ) maar dit verduidelik nog nie die ou vorms van die woord in Afrikaans nie, naamlik nonje en nunje. Hulle kom ooreen met die Kreoolse vorm in Macau nhonha ${ }^{4}$ ) wat afkomstig is van die populêre Portugese afkorting nhora ( $<$ Portugees senhora).44). Dit sluit egter nie die hipotese dat die twee vorms mekaar kon beinvloed uit nie: Afrikaans nonna < Portugees dona of Kreools nhonha < Portugees senhora (= vrou).

4. Sommige taalkundiges sien Portugese invloed op Afrikaans waar dit nie bestaan nie. Dit veroorsaak dat leenwoorde soms verkeerdelik aan Portugees toegeskryf word.

a) kakkerlak

Boshoff en Nienaber ${ }^{45}$ ) sien die oorsprong van hierdie woord in die Spaanse cucaracha of in die ou Portugees cacalacca. Ons kon egter nie hierdie woord in ou Portugees opspoor nie, maar wel in die Kreoolse Portugees van Batavia (kakkerlac) waar dit aan Nederlands ontleen is.46) Die opinie wat gehuldig word in die Woordeboek der Nederlandsche Taal lyk dan ook meer logies: hierdie woord het sy oorsprong in die tale van die Wes-Indiese gebiede waar dit later deel van die Nederlandse woordeskat geword het: ${ }^{7}$ ) Afrikaans kakkerlak < Nederlands kakkerlak (sedert end 17e eeu) < Wes-Indiese tale.

\section{b) piering}

Valkhoff voer aan dat die woord piering afkomstig is van die Portugees pires, ${ }^{48)}$ wat in Maleis piering geword het, maar dit is bewys dat pires van piering afgelei is en nie andersom nie. ${ }^{49}$ ) Gevolglik is dit logies dat die Afrikaanse piering nie aan Portugees ontleen is nie, maar wel aan Maleis: Afrikaans piering < Nederlands piering < Maleis piering.

5. Die vraag ontstaan of daar buiten die bekende woorde wat aan Portugees ontleen is, nie ander is wat tot nou toe aan ander stamwoorde toegeskryf is, maar in werklikheid Portugees van oorsprong is nie. 
a) troef

Boshoff en Nienaber sien die oorsprong van die Afrikaans en Nederlands troef in die Latyn triumphus (= Afrikaans oorwinning), wat na hulle mening deur die Franse triomphe (= Afrikaans oorwinning) ${ }^{60}$ ) in Afrikaans opgeneem is. Van Wijk stel die Spaanse stamwoord triunfo (= Afrikaans oorwinning) voor. ${ }^{\text {b1 })}$ Dit lyk egter vir ons of die Portugees woord trunfo (= Afrikaans troef), wat ons as stamwoord vir troef wil aanvaar, ${ }^{62}$ ) foneties en semanties nader aan die Nederlandse en Afrikaanse vorms kan wees: Afrikaans troef < Nederlands troef (sedert die 16e eeu) < Portufees trunfo < Latyn trimphu-

Gevolgtrekking:

Daar bestaan geen twyfel oor die bydrae van Portugees tot die Afrikaanse woordeskat nie. Nogtans het die probleme wat in hierdie artikel genoem word, die ondersoek na etimologieë in 'n mate gestrem. Dit is egter nie moeilik om tot die gevolgtrekking te kom dat, hoewel die invloed van Portugees op die Afrikaanse woordeskat reeds bestudeer is, ' $n$ hersiening en uitbreiding van huidige kennis tans nodig is nie.

$L A$ de $V$ Leal

P U vir C H O 
NOTAS:

1. Oor die Portugese koloniale uitbreiding sien, onder andere die duidelike ontleding van C R Boxer in The Portuguese Seaborne Empire: 1415 - 1825. Londen, Hutchinson, 1969.

2. Schuchardt, H "Beitrage" zur Kenntis des Kreolischen Romanisch" (v) Algemeineres über das Indoportugiesische (Asioportugiesische), Zeitschrift fur romanische Philologie. 13 (1889) p $476-524$.

3. Samarin, W J, "Linguas Francas of the World" in Readings in the sociology of Language, Den Haag, Mouton, 1970 p 660 - 672 .

4. As die Kreoolse tale uit die "pidgins" ontstaan, doen hulle dit deur enorme uitbreiding van taalkundige moontlikhede en baie ontlenings. (Taylor, D, "The Origin of West Indian Creole Languages: Evidence from grammatical categories", American Anthropologist, August 1963, p 801). Die moontlikheid dat hulle direk uit die standaardtaal kon ontstaan het, is nie uitgesluit nie. (Valkhoff, $M F$ New Light of A frikaans and Maleyo-Portuguese. Louvain, Editions Peeters, 1972, p 31.

5) Oor die "pidgins" en Kreoolse tale, sien Hall jr. $R$ A Pidgin and Creole Languages. New York, Cornell University Press, 1966 en Herculano de Carvalho, J G "Sobre a natureza e génese dos crioulos", Estudos Linguisticos. Coimbra, Atlântida, vol II, p $49-74$.

6) Nie al die verowerings van die Nederlanders was permanent nie. Die Portugese het Angola in 1648 herower en Brasilië in 1652- 54. Boxer C R, The Dutch Seaborne Empire. London, Hutchinson, 1965 , p $295-299$.

7. Boxer, C R, Four Centuries of Portuguese Expansion, $1415-1825$. $A$ succint survey. Johannesburg, W U P 1968, p $55-57$ en Dalgado S R, Dialecto Indo-Português de Ceylag, Lisboa, Imprensa Nacional, 1900, p XIX-XXI.

8. Lopes, $D$, Expansao da lingua portugyesa no Oriente nos séculos $X V I, X V I I$ en XVIII. Porto, Portucalense Editora, 1969, 2de uitgawe, p $93-100$.

9. Franken, J L M, Taalhistoriese Bydraes. Kaapstad, Balkema, 1953, p $41-79$.

10) Boshoff, S P E, en Nienaber, G S, Afrikaanse Etimologieë. Pretoria, S A Akademie, 1967, p 193.

11. Soos ons later sal sien, is die korrekte etimologie dourada.

12. Woordeboek der Nederlandsche Taal I-XX1, 1882 - Supplemente sedert 1942. S'Gravenhage, Nijhoff.

13. Van Wijk, N, Franck's Etymologisch Woordenboek der Nederlandsche Taal. S'Gravenhage, Nijhoff, 1912, 2 de druk.

14. De Vries, J, Nederlandse Erumologisch Woordenboek. Leiden. Brill, 1971.

15. Boshoff, S P E, en Nienaber, G S, op cit, p 142.

16. Schuchardt, $\mathrm{H}$, op cit, p 125.

17. Lopes, D, op cit, p 107 en 111 . Morais - Barbosa, J, A lingua portuguesa no mundo. Lisboa, Agência - Geral do Ultramar, 1966.

18. Machado, J P, Dicionário Erimológico da lingua portuguesa. Lisboa, Confluência, 1966, vol. II p 2189.

19. Onions, C J, The Oxford Dicrionary of English Etymology. Oxford Clarendon Presa, 1966, p 72. 
20. Lopes, D, op cit, p 107, Morais-Barbosa, J. op cit, p 135.

21. Boshoff, S P E, en Nienaber, G S, op cit p 152.

22. Machado, J P, op cit, vol I, p 312.

23. De Vries J, Op cit, p 29.

24. Lopes, D, op cit, p 34.

25. Dalgado, $\mathrm{S}$ R, op cit, p 51.

26. Boshoff, S P E, en Nienaber, G S, op cit, p 156.

27. Machado, J P, op cit, vol I, p 335.

28. Die Portugese etimologie is nie careta, soos Boshoff en Nienaber (op cit, p 338) ons wil oortuig nie.

29. Dalgado, $S \mathrm{R}$, op cit, p 143.

30. Schuchardt, H, op 'cit, p 120.

31) Almeida Costa, J, en Sampaio en Melo, A, Dicionário de Português. Porto, Porto Editora, s d, p 279.

32. Boshoff, S P E, en Nienaber, G S, op cit, p 133.

33. Dalgado, $\mathrm{S} R$, op cit, p 162.

34. Boshoff, S P E, en Nienaber, G S, op cit p 193

35. Ibidem, $p 22$.

36. Dalgado, S R, op cit, p 51.

37. Hierdie woord (fayson) bestaan nie in hedendaagse Afrikaans nie.

38. Franken, J L M, op cit, p 298.

39. Machado, J P, op cit, vol I, p 943.

40. Boshoff, S P E, en Nienaber, G S, op cit, p 298.

41. Machado, J P. op cit, vol I p 1091.

42. Boshoff, S P E, en Nienaber, G S, op cit, p 448.

43. Valkhoff, M F, Studies in Portuguese and Creole with special reference to South Africa. Johannesburg, W U P, 1966, p 239.

44. Morais-Barbosa, $J$ op cit, $p 126$.

45. Boshoff, S P E, en Nienaber, G S, op cit p 322.

46. Sehuchardt, $H$, op cit, p 137.

47. Woordenboek der Nederlandsche Taal onder Kakkerlak.

48. Valkhoff, M F, Studies, p 31.

49. Machado, J P, op cit, vol IL, p 1746.

50. Boshoff, S P E, en Nienaber, G S, op cit, p 658.

61. Van Wijk, N, op cit, p 709.

52. Die denasalisering is heeltemal moontlik: Afrikaans moesson Portugees moncao. 